\title{
A vulnerabilidade de populações indígenas: qualidade da água consumida pela comunidade Maxakali, Minas Gerais, Brasil
}

\section{The vulnerability of indigenous populations: water quality consumed by the Maxakali community, Minas Gerais, Brazil}

\author{
Eliseu Miranda de Assis ${ }^{1}$ \\ Emanuelle Marinho Santos ${ }^{2}$ \\ Márcia Cristina da Silva Faria ${ }^{3}$ \\ Jairo Lisboa Rodrigues ${ }^{4}$ \\ Anderson Garcez 5 \\ Cleide Aparecida Bomfeti ${ }^{6}$ \\ Nêmora Tregnago Barcellos ${ }^{7}$
}

\section{Palavras-chave:}

Qualidade da água

Água superficial

Água subterrânea

Índios Maxakali

Vulnerabilidade

\begin{abstract}
Resumo
Com aproximadamente 1800 indivíduos, distribuídos em quatro aldeias, o povo Maxakali é a segunda maior população indígena aldeada no Estado de Minas Gerais. A avaliação da qualidade da água utilizada para consumo e lazer nesta população geralmente é realizada por meio de critérios de palatabilidade e visuais. Dessa forma, realizou-se um estudo descritivo incluindo amostras de água superficial e subterrânea consumida em quatro aldeias, considerando a coleta em três períodos sazonais durante o ano de 2015. Foram mensurados o pH (potencial de hidrogeniônico), turbidez, concentração de oxigênio dissolvido, condutividade, nitrato, coliformes totais e termotolerantes. As aldeias com maior número de amostras com valores superiores aos toleráveis foram a Aldeia Verde (100\%), seguido da Aldeia Água Boa $(85,7 \%)$ e Pradinho $(71,4 \%)$. O oxigênio dissolvido e os coliformes totais e termotolerantes estiveram alterados em todas as aldeias, com percentuais superiores a $50 \%$ das amostras. A turbidez e a condutividade tiveram alterações detectadas em três das quatro aldeias analisadas. Assim, a água consumida por essa comunidade, in natura, conforme a tradição local, apresenta elevado risco para a ocorrência de doenças de veiculação hídrica nesse grupo populacional.
\end{abstract}

${ }_{1}$ Universidade do Vale do Rio dos Sinos (Unisinos). Programa de Pós-graduação em Saúde Coletiva. São Leopoldo, RS, Brazil. eliseumiranda@ifba.edu.br

2 Universidade Federal dos Vales do Jequitinhonha e Mucuri (UFVJM). Instituto de Ciência, Engenharia e

Tecnologia. Teófilo Otoni, MG, Brazil. emanuellemarinhosantos@gmail.com

${ }^{3}$ Universidade Federal dos Vales do Jequitinhonha e Mucuri (UFVJM). Instituto de Ciência, Engenharia e

Tecnologia. Teófilo Otoni, MG, Brazil. marcia.faria@ufvjm.edu.br

${ }^{4}$ Universidade Federal dos Vales do Jequitinhonha e Mucuri (UFVJM). Instituto de Ciência, Engenharia e

Tecnologia. Teófilo Otoni, MG, Brazil. jairo.rodrigues@ufvjm.edu.br

${ }^{5}$ Universidade do Vale do Rio dos Sinos (Unisinos). Programa de Pós-graduação em Saúde Coletiva. São Leopoldo, RS, Brazil. adsgarcez@gmail.com

6 Universidade Federal dos Vales do Jequitinhonha e Mucuri (UFVJM). Instituto de Ciência, Engenharia e

Tecnologia. Teófilo Otoni, MG, Brazil. cleide.bomfeti@ufvjm.edu.br

7 Universidade do Vale do Rio dos Sinos (Unisinos). Programa de Pós-graduação em Saúde Coletiva. São Leopoldo, RS, Brazil.nemoratb@gmail.com 
Keywords:

Water quality

Surface water

Groundwater

Maxakali's Indians

Vulnerability

\begin{abstract}
Distributed in four villages with approximately 1800 individuals, the Maxakali people is the second largest indigenous population in the state of Minas Gerais/Brazil. The evaluation of the quality of water used for consumption and leisure in this population is usually performed by palatability and visual criteria. Thus, a descriptive study was carried out including samples of surface and groundwater consumed in four villages, considering water collection in three seasonal periods in 2015. PH (hydrogen potential), turbidity, dissolved oxygen concentration, conductivity, nitrate, total and thermotolerant coliforms were measured. The villages with the largest number of samples with values higher than tolerable were Verde Village (100\%), followed by Agua Boa Village (85.7\%) and Pradinho (71.4\%). The dissolved oxygen, total and fecal coliforms were changed in all the villages, with percentages above $50 \%$ of the samples. The turbidity and conductivity changes were detected in three of the four villages. Thus, the water consumed by this community, in natura, according to local tradition, presents a high risk for the occurrence of waterborne diseases in this population group.
\end{abstract}

\section{INTRODUÇÃO}

As condições de saúde de uma população, assim como o desenvolvimento socioeconômico, estão relacionadas ao acesso à água em quantidade e qualidade. A prática de hábitos de higiene, associados ao acesso a água, aumenta a expectativa de vida, diminuindo as mortes prematuras. No entanto, mesmo sendo um direito humano básico, o acesso a água potável é uma realidade ainda distante nas áreas rurais e em regiões periurbanas carentes, levando a busca de fontes alternativas e com qualidade duvidosa, agravando ainda mais as já precárias condições de vida nessas localidades (RAZZOLINI; GÜNTHER, 2008).

A qualidade da água pode ser entendida como resultado das condições naturais e antrópicas em função do seu uso previsto (abastecimento domiciliar, irrigação, recreação, navegação, etc), sendo normatizadas no Brasil pela portaria do Ministério da Saúde 2914/2011 e pelas resoluções 357 de 2005 e 396 de 2008 do CONAMA (Conselho Nacional de Meio Ambiente). Sendo assim, mesmo que uma bacia hidrográfica seja preservada, isso por si só, não é garantia de uma água com boa qualidade para consumo, em virtude da possibilidade de sua contaminação ocorrer pelo escoamento superficial e pela infiltração, no solo, de produtos indesejáveis ao destino a que essa água se aplica (VON SPERLING, 1996). Nesse contexto, pode se entender que a água potável, aquela isenta de contaminantes químicos e microbiológicos, que se enquadra dentro de alguns parâmetros físicos e que também atenda certos requisitos de ordem estética (FERNANDES, 2012), importante para a saúde humana, ainda é bastante escassa para as populações residentes em áreas rurais ou em situações de aldeamento pela ausência dos serviços de saneamento (AMARAL et al., 2003).

Embora os riscos de adoecimento pelo consumo de uma água com qualidade duvidosa sejam comuns a qualquer sociedade, são as tradicionalmente mais vulneráveis que sofrem os maiores impactos, pelo somatório de condições como a escassez de alimentos, disposições inadequadas dos dejetos, ausência de tratamento sanitário, em geral associadas, e que favorecem o ciclo onde as condições sanitárias e as altas prevalências de parasitoses e desnutrição diminuem a capacidade da resposta fisiológica humana. Os Maxakali são a segunda maior população indígena aldeada de Minas Gerais, com aproximadamente 1800 indivíduos (BRASIL, 2013), e que apresenta altas taxas de mortalidade por desnutrição, conflitos internos acirrados pelo consumo de bebidas alcoólicas, doenças diarreicas e respiratórias (LAS CASAS, 2007), além de alta prevalência de parasitas intestinais (89\%) (ASSIS et al., 2013).

A comunidade indígena Maxakali se desloca entre aldeias e consome água in natura, caracterizada pela ausência de tratamento e muitas vezes escassa. Além disso, a avaliação da qualidade da água para essas comunidades se limita a critérios de palatabilidade e visuais, sendo insuficientes para garantir o padrão necessário à manutenção da saúde. Assim, no sentido de preencher essas lacunas, o presente estudo teve como objetivo diagnosticar as condições de qualidade da água distribuída a esse grupo, com avaliação dos padrões de natureza físico-química e microbiológica, avaliando a variação sazonal e a origem da fonte 
em todos os pontos utilizados para consumo e lazer nas quatro aldeias habitadas por essa comunidade.

\section{MATERIAL E MÉTODOS}

Um estudo descritivo transversal, com amostras de água coletadas em todas as fontes oficiais de captação pelo serviço de saneamento das aldeias, além de fontes não oficiais, nas quais foi identificado 0 consumo in natura pela comunidade indígena Maxakali, foi realizado em três períodos sazonais (seco, intermediário e chuvoso) de janeiro a julho de 2015. O projeto, embora não envolvesse seres humanos, foi submetido ao Comitê de Ética em pesquisa da Universidade Vale do Rio do Sinos-UNISINOS, e aprovado (parecer 129/2015). Lideranças indígenas e o Distrito Especial Indígena Minas Gerais/Espirito Santo (DSEI) também deram sua aprovação.

\section{Área de estudo}

O estudo foi realizado nas terras indígenas Maxakali, localizadas na região nordeste do estado de Minas Gerais e incluindo uma população total de 1832 indivíduos no ano de 2013 (BRASIL, 2013). O território corresponde às aldeias de Água Boa (município de Santa Helena de Minas com 699 indivíduos), Pradinho/Vila Nova (município de Bertópolis com 760 indivíduos), Aldeia Verde (município de Ladainha com 308 indivíduos) e Aldeia Cachoeirinha/Rafael no distrito de Topázio (município de Teófilo Otoni com 65 indivíduos) (Figura 1). Um total de vinte e quatro pontos foram mapeados como fontes de consumo de água, sendo na maioria poços artesianos ou barragens feitas em algumas nascentes. Entretanto, algumas lagoas ou rios onde não eram coletadas água para distribuição, mas que havia por parte da comunidade o hábito de usar esses locais para recreação (banho, lazer), também foram mapeados como parte do estudo, uma vez que também eram locais de consumo da água in natura (Figura 1).

As maiores aldeias em extensão territorial e populacional são as Aldeias Pradinho (Vila Nova) e Água Boa, com uma área de aproximadamente 5.305 hectares, próxima à divisa dos estados de Minas Gerais com o Espírito Santo e Bahia. Hidrograficamente, estas duas áreas indígenas estão localizadas nas cabeceiras de afluentes do Rio Itanhém, bacia hidrográfica do Rio Itanhém, que deságua no Oceano Atlântico na cidade de Alcobaça/BA. Política e administrativamente elas pertencem à região do Vale do Mucuri, região Nordeste de Minas Gerais. A Aldeia Verde está situada no município de Ladainha/MG e sua área é de 552 hectares, com predominância de morros e solo de baixa fertilidade (CARVALHO; ALVES, 2009), e a Aldeia Cachoeirinha/Rafael, em Topázio, distrito de Teófilo Otoni/MG, existe há menos de nove anos, sendo uma fazenda adquirida pela FUNAI, com pouca infraestrutura de estradas e com ausência de saneamento básico. Tanto a Aldeia Verde, quanto a Rafael estão localizadas na bacia hidrográfica do Rio Mucuri.

\section{Procedimentos de coleta das amostras de água}

A primeira coleta ocorreu em janeiro de 2015, considerado pelo calendário climático como o período chuvoso para a região. Entretanto, neste período não houve chuva. A segunda coleta foi realizada no mês de abril de 2015, período intermediário pelo calendário climático, quando as temperaturas estiveram amenas, ainda sem chuvas volumosas, mas com discretas precipitações, insuficientes para recarga dos rios, córregos e poços. A terceira coleta foi realizada em julho, quando o calendário climático previa seca, porém, a mesma foi feita sob fortes chuvas. As variações climáticas não impactaram no estudo, uma vez que se pretendia avaliar momentos de maior diluição e carreamento favorecidos pela chuva e de menor diluição favorecidos pela seca.

As amostras coletadas foram identificadas, armazenadas em caixa térmica com temperatura controlada e encaminhadas imediatamente para o processamento, respeitando o limite máximo de quatro horas entre a coleta e o início das análises. Ademais, para a coleta das amostras foi adotado o procedimento recomendado pela Companhia de Tecnologia de Saneamento Ambiental (CETESB, 2011), com amostragem realizada em frascos de polipropileno de $50 \mathrm{~mL}$ com tampa livre de metais. Cada coleta foi realizada em três momentos, com critério sazonal (período seco, intermediário e chuvoso). 
Figura 1. Localização da área do estudo com os pontos de coletas nas quatro aldeias indígenas Maxakali.

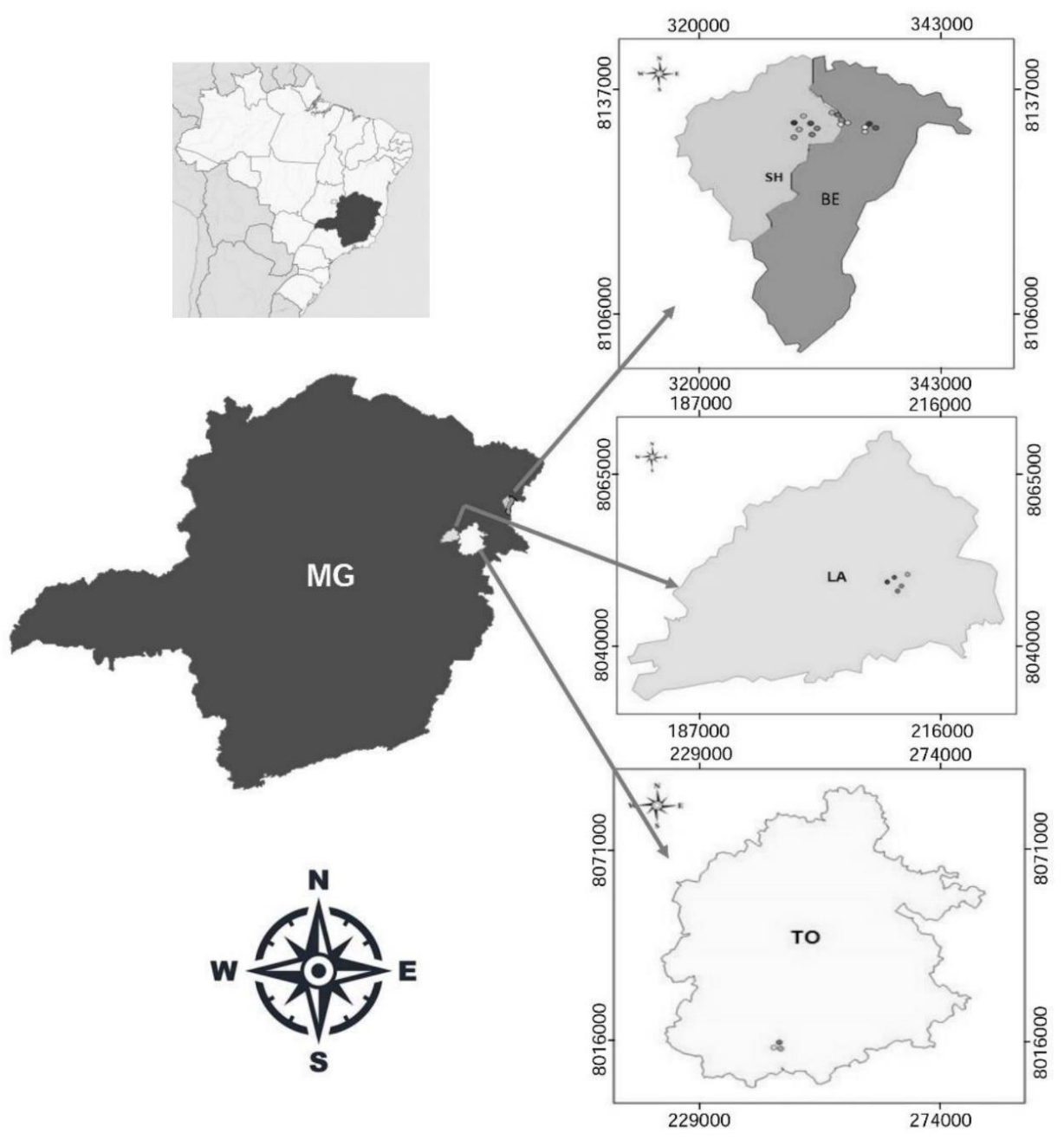

Legenda: BE, Município de Bertópolis: Aldeia Pradinho; SH, Município de Santa Helena de Minas: Aldeia Água Boa; LA, Município de Ladainha: Aldeia Verde; TO, Município de Teófilo Otoni (Distrito Topázio): Aldeia Rafael. Fonte: Org.: do Autor, 2017.

\section{Determinação dos parâmetros físico- químicos}

As análises dos parâmetros físico-químicos seguiram a metodologia descrita por Macêdo (2001). Para a determinação do pH (potencial de hidrogeniônico), foi utilizado um potenciômetro (pHmetro) modelo DM-22 (Digimed). A determinação da turbidez foi realizada pelo método nefelométrico, utilizando o aparelho turbidímetro, modelo HI 98703-11, fabricado e distribuído pela empresa Hanna Brasil. Esse instrumento mede a turbidez de uma amostra na faixa de 0.00 a 1000 NTU (Unidades Nefelométricas de Turbidez). A concentração de oxigênio dissolvido foi medido utilizando-se de um equipamento oxímetro portátil, produzido pela empresa brasileira Digimed, modelo DM-4P, com limites de medição entre 0 a $60 \mathrm{mg}$ O2/L. A condução da corrente elétrica foi medida utilizando-se de um condutivímetro mCA-150p distribuído no Brasil pela empresa MS Tecnopon Equipamentos Especiais Ltda, com faixa de leitura em águas de 0 a $200.000 \mu \mathrm{S} / \mathrm{cm}$. Todos os equipamentos utilizados nesta avaliação foram calibrados antes de cada leitura, seguindo as recomendações do fabricante.

Para avaliação do conteúdo de nitrogênio, na forma de nitrato na água, foi utilizado o método que aplica a luz ultravioleta seletiva, por ser rápido e de fácil execução. As amostras foram analisadas imediatamente após o preparo. Para remover as possíveis interferências por partículas em suspensão, as amostras foram filtradas. Após a filtração, foi adicionado $1,0 \mathrm{ml}$ de $\mathrm{HCl} 1 \mathrm{M}$ em cada amostra para a acidificação, 
prevenindo interferências de hidróxidos ou carbonatos até $1000 \mathrm{mg} / \mathrm{L}$, sendo submetidas à espectrofotometria utilizando um comprimento de onda de $220 \mathrm{~nm}$ para obter a leitura de NO3e $275 \mathrm{~nm}$ para determinar a interferência pela matéria orgânica dissolvida. Houve correção para absorção não específica (oriunda de matéria orgânica porventura presente) e posterior comparação com a curva padrão previamente estabelecida. Esta correção foi baseada na leitura da absorção em $275 \mathrm{~nm}$, onde nitrato não absorve. Para a preparação da solução estoque de nitrato (100 mg L-1) pesou-se 0,1629 g de nitrato de potássio PA (KNO3) (Sigma), seco a $105{ }^{\circ} \mathrm{C}$ por 24 horas, e transferiu-se para um balão volumétrico de $1000 \mathrm{~mL}$ e completado com água ultrapura $(18 \Omega \mathrm{m})$. Já para a curva de calibração, preparou-se padrões no intervalo entre 0,0 e 7,0 mg/L de NO3-N em balões de 100 $\mathrm{ml}$, a partir da solução estoque, e adicionou-se a cada balão $1 \mathrm{~mL}$ de ácido clorídrico $1 \mathrm{M}$ com posterior homogeneização (APHA, 2012).

A análise microbiológica foi obtida pela técnica dos tubos múltiplos para determinação de coliformes totais e termotolerantes, conforme estabelecido pelo Manual Prático de Análise de Água da Fundação Nacional de Saúde (BRASIL, 2009). Para a determinação de coliformes totais e termotolerantes foi diluído $1 \mathrm{~mL}$ de cada amostra em solução salina $(0,85 \%$ de $\mathrm{NaCl})$, totalizando seis diluições decimais. Para cada diluição foi retirado $1 \mathrm{~mL}$ da solução e inoculada em meio de cultura caldo Lauril Triptose Sulfato (LST) contido em tubos de ensaio com tubo de Duhran invertido em seu interior, totalizando três repetições para cada diluição.

Os tubos foram incubados em estufa de cultura a $35^{\circ} \mathrm{C}$ por 48 horas. Após incubação, aqueles tubos que apresentaram resultado positivo, isto é, turvação do meio de cultura e formação de gás dentro do tubo de Duhran, foram inoculados em caldo Verde Brilhante (VB) e caldo Escherichia coli (EC) para confirmação de coliformes totais e coliformes termotolerantes, respectivamente. Para tanto, retirou-se uma alíquota de $100 \mu$ l de cada tubo considerado positivo e inoculou-se em tubos contendo os meios de cultura acima citados, sendo os mesmos incubados a $35^{\circ} \mathrm{C}$ e $45^{\circ} \mathrm{C}$ por 48 horas, respectivamente. Após a incubação verificou-se a formação de gás no interior do tubo de Duhran e turvação do meio de cultura, tomando como positivos os tubos que apresentaram tais características.

A partir do número de tubos com reação negativa e positiva nos caldos VB e EC, e utilizando a tabela do Número Mais Provável (NMP), foi determinado o NMP/mL de coliformes totais e de coliformes termotolerantes, quantificando o número dessas bactérias para cada mililitro de amostra de água.

\section{Processamento e análise dos dados coletados}

Os resultados foram digitados (com dupla entrada e correção de inconsistências) no SPSS (Software Statistical Package for the Social Scienses), versão 22 (SPSS Inc., Chicago, IL, EUA) para a análise estatística. Variáveis foram criadas para cada ponto de corte (valor máximo em relação as portarias do Ministério da Saúde 2914/2011 (BRASIL, 2011), CONAMA 396 (BRASIL, 2008), e 357 (BRASIL, 2005) e sazonalidade. Utilizou-se teste não paramétrico de Mann-Whitney para a realização de comparação de médias dos resultados das análises dos parâmetros, em relação a origem da água (superficial versus subterrânea), considerando que os dados não apresentaram distribuição normal (dados assimétricos). Todas as análises dos dados foram executadas em relação ao ponto da coleta, a aldeia, a sazonalidade (seco, intermediário e chuvoso) e quanto à origem da água (superficial ou subterrânea). Tabela complementar, com os valores absolutos das análises e os respectivos valores de referências, está disponível no endereço eletrônico: https://goo.gl/EurYiT.

\section{RESULTADOS}

$\mathrm{O} \mathrm{pH}$ foi o item avaliado com menor percentual de desvio da faixa de normalidade. O oxigênio dissolvido, assim como a presença de coliformes totais e termotolerantes, tiveram resultados impróprios em todas as aldeias, com percentuais superiores a $50 \%$ das amostras. A turbidez e a condutividade mostraram resultados fora dos padrões, para o tipo de destino e valor máximo permitido (VMP), em três das quatro aldeias participantes e o nitrato em duas (Tabela 1). As aldeias com maior comprometimento em relação aos itens avaliados foram a Aldeia Verde (100\%), seguidas da Aldeia Água Boa (85,7\%) e Pradinho (71,4\%). Com menor percentual de alteração, em relação aos padrões estabelecidos, encontramos a Aldeia Rafael (57,1\%). 
Tabela 1. Percentual de alterações físico-químicas e microbiológicas na água consumida nas aldeias Maxakali.

\begin{tabular}{|c|c|c|c|c|c|c|c|c|}
\hline \multirow[b]{2}{*}{ Itens analisados } & \multicolumn{8}{|c|}{ Aldeias } \\
\hline & $\begin{array}{c}\text { Pradinho } \\
(\mathrm{n} / \mathrm{N})\end{array}$ & $(\%)$ & $\begin{array}{c}\text { Agua Boa } \\
(\mathrm{n} / \mathrm{N})\end{array}$ & (\%) & $\begin{array}{c}\text { Verde } \\
(\mathrm{n} / \mathrm{N})\end{array}$ & $(\%)$ & $\begin{array}{l}\text { Rafael } \\
(\mathrm{n} / \mathrm{N})\end{array}$ & (\%) \\
\hline $\mathrm{pH}^{*}$ & & - & - & & $02 / 15$ & 13 & $01 / 09$ & 11 \\
\hline Oxigênio** & $19 / 27$ & 70 & $12 / 21$ & 57 & $08 / 15$ & 53 & 06/09 & 67 \\
\hline Turbidez & $08 / 27$ & 30 & $04 / 21$ & 19 & $01 / 15$ & 7 & - & - \\
\hline Condutividade & $24 / 27$ & 89 & $12 / 21$ & 57 & $01 / 15$ & 7 & - & - \\
\hline Nitrato & - & - & $02 / 21$ & 9,5 & $02 / 15$ & 13 & - & - \\
\hline Colif. Totaisa & $15 / 27$ & 55,5 & $17 / 21$ & 81 & $09 / 15$ & 60 & 07/09 & 78 \\
\hline Colif. Termotb & $18 / 27$ & 67 & $19 / 21$ & 90 & $11 / 15$ & 73 & 06/09 & 67 \\
\hline
\end{tabular}

*-Potencial de Hidrogênio, **-Oxigênio dissolvido, a- coliformes totais, b- coliformes termotolerantes, nnúmero de amostras alteradas, N- número de coletas realizadas, (-) amostras sem alterações ou com valor Inferior ao limite máximo permitido.

$\mathrm{O} \quad \mathrm{pH}$ apresentou-se discretamente alterado para o limite inferior em relação à legislação brasileira $(6,0$ - 9,0) em dois pontos da Aldeia Verde (AV2 e AV3) e em um ponto da Aldeia Rafael (AR2). Essa alteração ocorreu apenas no período intermediário em relação ao clima (Tabela 2).

Foram considerados como valores impróprios para o oxigênio dissolvido, aqueles na faixa inferior a $6 \mathrm{mg} / \mathrm{L}$. Nas $72(100 \%)$ análises para esse parâmetro, $45(62,5 \%)$ mostraram-se alteradas. Os valores mínimos (0,52 mg/L), $(0,88$ $\mathrm{mg} / \mathrm{L})$ e $(0,91 \mathrm{mg} / \mathrm{L})$ foram observados em dois pontos da Aldeia Pradinho (AP5 e AP6) e em um ponto na Aldeia Água Boa (AB3). O período intermediário foi o mais crítico, com $95,8 \%$ de amostras alteradas (Tabela 2).

As resoluções do CONAMA 357/2005 e 396/2008 estabelece o limite inferior a 40 NTU (unidade de turbidez nefelométrica) na turbidez como padrão de potabilidade para águas de classe I (águas destinadas ao abastecimento doméstico após tratamento simplificado). Nas medições realizadas, este item mostrou-se alterado em 19,4\% das amostras, embora em $42,8 \%$ delas, as medidas mostraram valor entre 40 e 50 NTU. Dois locais da Aldeia Pradinho apresentaram valores elevados, chegando a ser superior ao limite de deteç̧ão do equipamento no ponto AP6, e sendo observado o valor de 1000 NTU no ponto AP5. Essas alterações foram encontradas no período seco.

A condutividade tem como VMP para águas classe I, valor inferior a $100 \mu \mathrm{S} / \mathrm{cm}$
(microSiemens por centímetro). Na Aldeia Verde, no ponto AV5, foi observada a maior alteração no período seco $(1056 \mu \mathrm{S})$. No período intermediário, a maior alteração no valor da condutividade foi observada na Aldeia Pradinho $(654 \mu \mathrm{S})$, no ponto $\mathrm{AP} 3$, enquanto que no período chuvoso, o maior desvio, em relação à normalidade, foi observado na mesma aldeia, no ponto AP1 $(606 \mu \mathrm{S})$. Na Aldeia Pradinho apenas o ponto AP4 apresentou condutividade da água dentro dos padrões recomendados. Na Aldeia Água Boa, as alterações estiveram presentes nos três momentos sazonais nos pontos $\mathrm{AB} 1$ a $\mathrm{AB} 4$. Na Aldeia Rafael a condutividade se mostrou normal em todas as fontes que tiveram suas águas coletadas. Na Aldeia Pradinho, 8 dos nove pontos apresentaram condutividade alterada nos três períodos das coletas (seco, intermediário e chuvoso).

O Nitrato tem valor preconizado como inferior a $10 \mathrm{mg} / \mathrm{L}$ para águas de classe I. Foram encontradas duas alterações para esse elemento no período seco na Aldeia Água Boa (AB3 e AB4), uma delas sendo o maior valor em todas as análises $(160,71 \mathrm{mg} / \mathrm{L})$. No período chuvoso foi observado três alterações na Aldeia Verde (AV1, $\mathrm{AV} 2$ e AV4). Exceto no ponto AB4, todos os demais valores encontrados nas amostras foram inferiores a $15 \mathrm{mg} / \mathrm{L}$.

Quanto à avaliação para os coliformes totais e os termotolerantes, todos os pontos apresentaram alterações em algum momento do estudo (Tabela 2). 
Tabela 2. Parâmetros físico-químicos e microbiológicos com dosagem alterada, de acordo com sazonalidade, em cada ponto de coleta.

\begin{tabular}{|c|c|c|c|c|c|c|c|c|c|}
\hline Aldeias & Pontos & $p H^{*}$ & Oxigênio** & Turb. $^{a}$ & Cond.b & Nitrato & $\begin{array}{c}\text { Colif. } \\
\text { Totais }\end{array}$ & $\begin{array}{c}\text { Colif. } \\
\text { Termot }^{\mathrm{d}}\end{array}$ & $\begin{array}{c}\text { Total de } \\
\text { alterações }\end{array}$ \\
\hline \multirow{9}{*}{ Pradinho } & AP1 & - & $2(\mathrm{I} / \mathrm{C})$ & $2(\mathrm{I} / \mathrm{C})$ & $3(\mathrm{~S} / \mathrm{I} / \mathrm{C})$ & - & $2(\mathrm{~S} / \mathrm{I})$ & $2(\mathrm{~S} / \mathrm{I})$ & 11 \\
\hline & AP2 & - & $2(\mathrm{I} / \mathrm{C})$ & - & $3(\mathrm{~S} / \mathrm{I} / \mathrm{C})$ & - & $1(\mathrm{~S})$ & $2(\mathrm{~S} / \mathrm{C})$ & 8 \\
\hline & AP3 & - & $1(\mathrm{I})$ & - & $3(\mathrm{~S} / \mathrm{I} / \mathrm{C})$ & - & $1(\mathrm{~S})$ & $2(\mathrm{~S} / \mathrm{C})$ & 7 \\
\hline & $\mathrm{AP} 4$ & - & $2(\mathrm{~S} / \mathrm{I})$ & - & - & - & $3(\mathrm{~S} / \mathrm{I} / \mathrm{C})$ & $3(\mathrm{~S} / \mathrm{I} / \mathrm{C})$ & 8 \\
\hline & AP5 & - & $2(\mathrm{I} / \mathrm{C})$ & $2(\mathrm{~S} / \mathrm{C})$ & $3(\mathrm{~S} / \mathrm{I} / \mathrm{C})$ & - & $3(\mathrm{~S} / \mathrm{I} / \mathrm{C})$ & $3(\mathrm{~S} / \mathrm{I} / \mathrm{C})$ & 13 \\
\hline & AP6 & - & $3(\mathrm{~S} / \mathrm{I} / \mathrm{C})$ & $3(\mathrm{~S} / \mathrm{I} / \mathrm{C})$ & $3(\mathrm{~S} / \mathrm{I} / \mathrm{C})$ & - & $3(\mathrm{~S} / \mathrm{I} / \mathrm{C})$ & $3(\mathrm{~S} / \mathrm{I} / \mathrm{C})$ & 15 \\
\hline & AP7 & - & $3(\mathrm{~S} / \mathrm{I} / \mathrm{C})$ & $1(\mathrm{C})$ & $3(\mathrm{~S} / \mathrm{I} / \mathrm{C})$ & - & $1(\mathrm{~S})$ & $1(\mathrm{I})$ & 9 \\
\hline & AP8 & - & $3(\mathrm{~S} / \mathrm{I} / \mathrm{C})$ & - & $3(\mathrm{~S} / \mathrm{I} / \mathrm{C})$ & - & $1(\mathrm{I})$ & $1(\mathrm{I})$ & 8 \\
\hline & AP9 & - & $1(\mathrm{I})$ & $1(\mathrm{C})$ & $3(\mathrm{~S} / \mathrm{I} / \mathrm{C})$ & - & - & $1(\mathrm{I})$ & 6 \\
\hline \multirow{7}{*}{ Água Boa } & $\mathrm{AB} 1$ & - & $2(\mathrm{I} / \mathrm{C})$ & $1(\mathrm{C})$ & $3(\mathrm{~S} / \mathrm{I} / \mathrm{C})$ & - & $2(\mathrm{~S} / \mathrm{I})$ & $2(\mathrm{~S} / \mathrm{I})$ & 10 \\
\hline & AB2 & - & $2(\mathrm{I} / \mathrm{C})$ & $1(\mathrm{I})$ & $3(\mathrm{~S} / \mathrm{I} / \mathrm{C})$ & - & $2(\mathrm{~S} / \mathrm{I})$ & $3(\mathrm{~S} / \mathrm{I} / \mathrm{C})$ & 11 \\
\hline & AB3 & - & $2(\mathrm{I} / \mathrm{C})$ & $1(\mathrm{I})$ & $3(\mathrm{~S} / \mathrm{I} / \mathrm{C})$ & $1(\mathrm{~S})$ & $2(\mathrm{~S} / \mathrm{I})$ & $2(\mathrm{~S} / \mathrm{I})$ & 11 \\
\hline & $\mathrm{AB} 4$ & - & $2(\mathrm{I} / \mathrm{C})$ & $1(\mathrm{~S})$ & $3(\mathrm{~S} / \mathrm{I} / \mathrm{C})$ & $1(\mathrm{~S})$ & $3(\mathrm{~S} / \mathrm{I} / \mathrm{C})$ & $3(\mathrm{~S} / \mathrm{I} / \mathrm{C})$ & 13 \\
\hline & AB5 & - & $1(\mathrm{I})$ & - & - & - & $3(\mathrm{~S} / \mathrm{I} / \mathrm{C})$ & $3(\mathrm{~S} / \mathrm{I} / \mathrm{C})$ & 7 \\
\hline & $\mathrm{AB} 6$ & - & $2(\mathrm{I} / \mathrm{C})$ & - & - & - & $2(\mathrm{~S} / \mathrm{I})$ & $3(\mathrm{~S} / \mathrm{I} / \mathrm{C})$ & 7 \\
\hline & AB7 & - & $1(\mathrm{I})$ & - & - & - & $3(\mathrm{~S} / \mathrm{I} / \mathrm{C})$ & $3(\mathrm{~S} / \mathrm{I} / \mathrm{C})$ & 7 \\
\hline \multirow{5}{*}{ Verde } & AV1 & - & $1(\mathrm{C})$ & - & - & $1(\mathrm{C})$ & $3(\mathrm{~S} / \mathrm{I} / \mathrm{C})$ & $3(\mathrm{~S} / \mathrm{I} / \mathrm{C})$ & 8 \\
\hline & AV2 & $1(\mathrm{I})$ & $2(\mathrm{I} / \mathrm{C})$ & - & - & - & $1(\mathrm{~S})$ & $2(\mathrm{~S} / \mathrm{C})$ & 6 \\
\hline & AV3 & $1(\mathrm{I})$ & $1(\mathrm{I})$ & - & - & - & $1(\mathrm{C})$ & - & 3 \\
\hline & $\mathrm{AV} 4$ & & $2(\mathrm{I} / \mathrm{C})$ & & - & $1(\mathrm{C})$ & $2(\mathrm{~S} / \mathrm{I})$ & $3(\mathrm{~S} / \mathrm{I} / \mathrm{C})$ & 8 \\
\hline & AV5 & - & $2(\mathrm{I} / \mathrm{C})$ & $1(\mathrm{~S})$ & $1(\mathrm{~S})$ & - & $2(\mathrm{~S} / \mathrm{I})$ & $3(\mathrm{~S} / \mathrm{I} / \mathrm{C})$ & 9 \\
\hline \multirow{3}{*}{ Rafael } & AR1 & - & $2(\mathrm{I} / \mathrm{C})$ & - & - & - & $3(\mathrm{~S} / \mathrm{I} / \mathrm{C})$ & $2(\mathrm{I} / \mathrm{C})$ & 7 \\
\hline & AR2 & $1(\mathrm{I})$ & $2(\mathrm{I} / \mathrm{C})$ & - & - & - & $2(\mathrm{~S} / \mathrm{I})$ & $2(\mathrm{I} / \mathrm{C})$ & 7 \\
\hline & AR3 & - & $2(\mathrm{I} / \mathrm{C})$ & - & - & - & $2(\mathrm{~S} / \mathrm{I})$ & $2(\mathrm{I} / \mathrm{C})$ & 6 \\
\hline $\begin{array}{r}\text { Total de ponto } \\
\text { alterada par } \\
\text { analisad }\end{array}$ & $\begin{array}{l}\text { om medida } \\
\text { ada item } \\
\text { N-72) }\end{array}$ & 3 & 45 & 14 & 37 & 4 & 48 & 54 & \\
\hline
\end{tabular}

*-Potencial de Hidrogênio, **-Oxigênio dissolvido, a-Turbidez, b-Condutividade, c- coliformes totais, d- coliformes termotolerantes, S-período de seca; I-período intermediário; C-período de chuvas, (-) Inferior ao limite máximo permitido ou ao limite de deteç̧ão do equipamento.

Em relação a sazonalidade, todos os períodos analisados mantiveram o mesmo percentual de alteração em relação aos itens avaliados. Dos sete itens, 06 estiveram alterados, independente do momento em que foi coletado, com exceção do pH que só demonstrou alteração no período intermediário. O oxigênio dissolvido, com $95,6 \%$ de seus valores abaixo do permitido, foi o item avaliado que apresentou o maior número de alterações em relação ao período sazonal (vinte e três das 24 amostras alteradas). Para a condutividade, a turbidez, e o nitrato, o percentual de amostras alteradas foi aproximadamente o mesmo nos três períodos avaliados.

$\mathrm{Na}$ avaliação microbiológica para os coliformes, foram encontradas concentrações acima do permitido em todos os períodos avaliados, entretanto para os coliformes totais, o período chuvoso teve um percentual inferior a $50 \%$ de amostras fora dos padrões. As demais medidas, tanto para os coliformes totais quanto para os termotolerantes, apresentaram um percentual de amostras alteradas superiores a $70 \%$, chegando a $83,3 \%$ no período intermediário para os coliformes termotolerantes (Tabela 3).

A condutividade e o nitrato apresentaram um maior número de alterações em águas de origem superficial, contudo a média de condutividade foi significativamente maior na água de origem subterrânea. O oxigênio dissolvido e os coliformes termotolerantes apresentaram concentrações alteradas, tanto em águas superficiais quanto em subterrâneas, porém sem significância estatística quando comparado às médias dos valores. Embora todas as fontes de águas de origem superficiais e subterrâneas tenham apresentado contaminação por coliformes termotolerantes, destaca-se entre os resultados, o percentual de $100 \%$ de contaminação para as fontes de origem subterrâneas e o seu valor médio no número mais provável de colônias sendo superior às fontes de origem superficiais (Tabela 4). 
Tabela 3. Percentual de alteração físico-química e microbiológica por período sazonal.

\begin{tabular}{|c|c|c|c|c|c|c|c|c|c|}
\hline \multirow[b]{2}{*}{ Itens avaliados } & \multicolumn{3}{|c|}{ Seco } & \multicolumn{3}{|c|}{ Intermediário } & \multicolumn{3}{|c|}{ Chuvoso } \\
\hline & $\begin{array}{c}\text { Amostras } \\
\text { alteradas } \\
\text { N } 24\end{array}$ & $\%$ & Máx/Min & $\begin{array}{c}\text { Amostras } \\
\text { alteradas } \\
\text { N } 24\end{array}$ & $\%$ & Máx/Min & $\begin{array}{c}\text { Amostras } \\
\text { alteradas } \\
\text { N } 24\end{array}$ & $\%$ & Máx/Min \\
\hline $\begin{array}{c}\text { pH } \\
\text { VMP 6-9 }\end{array}$ & - & - & $8,13 / 6,2$ & 3 & 12,5 & $6,99 / 5,53$ & - & - & $8,21 / 6,7$ \\
\hline $\begin{array}{c}\text { Oxigênio* } \\
\text { VMP > } 6 \text { mg/l }\end{array}$ & 4 & 16,6 & $21,58 / 1,31$ & 23 & 95,8 & $6,77 / 0,52$ & 18 & 75 & $7,63 / 0,88$ \\
\hline $\begin{array}{c}\text { Turbidez } \\
\text { VMP }<40 \text { NTU }\end{array}$ & 4 & 16,6 & $>1000 / 1,88$ & 4 & 16,6 & $63,7 / 1,31$ & 5 & 20,8 & $318 / 1,35$ \\
\hline $\begin{array}{l}\text { Condutividade } \\
\text { VMP }<100 \mu \mathrm{S}\end{array}$ & 13 & 54,1 & $767 / 32,8$ & 12 & 50 & $649 / 18,7$ & 12 & 50 & $606 / 18,6$ \\
\hline $\begin{array}{c}\text { Nitrato } \\
\text { VMP }<10 \mathrm{mg} / \mathrm{l}\end{array}$ & 2 & 8,3 & $160,7 / 0,01$ & - & - & $2,18 / 0,09$ & 3 & 12,5 & $14,48 / 0,08$ \\
\hline $\begin{array}{l}\text { Col.Totais } \\
\text { VMP: ausência } \\
\text { em } 100 \mathrm{ml}\end{array}$ & 20 & 83,3 & $930 / 0$ & 19 & 79,1 & $>11000 / 0$ & 9 & 37,5 & $43 / 0$ \\
\hline $\begin{array}{l}\text { Col.Terb } \\
\text { VMP: ausência } \\
\text { em } 100 \mathrm{ml}\end{array}$ & 17 & 70,8 & $2400 / 0$ & 20 & 83,3 & $>11000 / 0$ & 17 & 70,8 & $1100 / 0$ \\
\hline
\end{tabular}

pH- Potencial de Hidrogênio, *-Oxigênio dissolvido, a- Coliformes totais, b- Coliformes termotolerantes, (-) amostras sem alteração. VMP- Valor máximo permitido em relação as portarias do Ministério da Saúde 2914/2011, CONAMA 357 e 396. Máx valor máximo observado nas análises, Min- Valor mínimo observado nas análises.

Tabela 4: Média de valores encontrados nas variáveis físico-químicas e microbiológicas, por origem da fonte da água nas aldeias Maxakali.

\begin{tabular}{ccccccc}
\hline \multirow{2}{*}{ Variável } & \multirow{2}{*}{ VMP } & \multicolumn{2}{c}{ Superficial } & \multicolumn{2}{c}{ Subterrânea } & \multirow{2}{*}{ P-valor* } \\
\cline { 3 - 6 } & & Media & Dp & Media & Dp & \\
pH & $6-9$ & 6,97 & 0,11 & 6,95 & 0,20 & 0,837 \\
$\mathbf{O}_{2}$ & $>6 \mathrm{mg} / \mathrm{l}$ & 5,86 & 2,02 & 6,34 & 1,75 & 0,639 \\
Turbidez & $<40 \mathrm{NTU}$ & 68,01 & 126,77 & 33,89 & 38,29 & 0,519 \\
Condutividade & $<100 \mu \mathrm{S}$ & 69,44 & 96,15 & 253,43 & 137,98 & 0,004 \\
$\quad$ Nitrato & $<10 \mu \mathrm{g} / \mathrm{L}$ & 6,55 & 13,89 & 1,14 & 1,30 & 0,061 \\
Col_termot & Ausência em & \multirow{2}{*}{146,21} & 223,77 & \multirow{2}{*}{177,72} & 480,85 & 0,379 \\
$\quad(\boldsymbol{E}$.Coli) & $100 \mathrm{ml}$ & &
\end{tabular}

pH- Potencial de Hidrogênio, $\mathrm{O}_{2}$ - Oxigênio dissolvido, Col_Termot- Coliformes Termotolerantes; VMP-Valor máximo permitido em relação as portarias do Ministério da Saúde 2914/2011, CONAMA 357 e $396 .{ }^{* P}$-valor para teste não paramétrico de Mann-Whitney.

\section{DISCUSSÃO}

A ideia de contaminação das águas, entendendose por contaminação a ocorrência de um elemento em teor superior ao nível basal em uma determinada área (PIERZYNSKI; VANCE; SIMS, 2005), é atribuída, principalmente, à poluição ambiental (GONÇALVES; ARAÚJO; FERREIRA, 2003), tendo na falta de políticas para o meio ambiente e a educação sanitária, os fatores contribuintes para a elevação das taxas de parasitismo no Brasil. Doenças diarreicas de veiculação hídrica já foram responsáveis por vários surtos epidêmicos e por elevadas taxas de mortalidade infantil (BROOKS et al., 2014; MACÊDO, 2001; PELCZAR JR et al., 1996), inclusive na comunidade indígena Maxakali
(ASSIS et al., 2013).

Inquérito realizado na comunidade indígena Maxakali, em 2009 (ASSIS et al., 2013), identificou que, quanto ao tratamento da água, nenhuma forma era utilizada; além disso, outras fontes de água, que não a captada pelo sistema de saneamento das aldeias, eram usadas para a higiene e consumo, com inadequado armazenamento em todas as 187 residências. Em relação aos dejetos humanos, $139(73,9 \%)$ dos domicílios investigados não possuíam vasos sanitários. Dos que possuíam, 19 (10,1\%) despejavam a água do vaso sanitário em fossas e $29(15,4 \%)$ no próprio terreno (ASSIS et al., 2013).

Embora existam vários estudos no Brasil (AMARAL et al., 2003; GIACOMETTI, 2001; QUEIROZ et al., 2002), avaliando a qualidade da 
água para o consumo humano, estes são mais raros em comunidades indígenas, mesmo tendo ela um significado distinto e maior para esses grupos. A água remete, nos povos indígenas, a mitos que associam a origem de algumas dessas sociedades diretamente à sua presença, sendo considerada como um ser vivo que deve ser respeitado (DIEGUES, 1998). Além disso, a maioria dos estudos avaliaram a qualidade da água antes da oferta ao consumo, que pressupõe o tratamento preconizado pela legislação em vigor quando do consumo, o que minimiza a maioria dos riscos identificados. $\mathrm{Na}$ comunidade Indígena Maxakali pesa o fato da oferta ao consumo ocorrer sem qualquer tratamento específico.

As aldeias Maxakali ocupam áreas que apresentam um dos menores IDHs (Índice de Desenvolvimento Humano) do Brasil e, mesmo não tendo grandes fontes poluidoras, apresentam atividades antrópicas e têm, na pecuária de pequeno porte, sua principal atividade produtiva (ROMERO, 2006). As características seculares de mobilidade dessa população, somada às longas caminhadas entre as aldeias, favorecem o consumo de água com qualidade insatisfatória durante o trajeto, incluindo o consumo nas aldeias com as piores avaliações. Além disso, a litologia das rochas, assim como as variações climáticas nesta região podem, em grande parte, justificar a maioria das alterações físico-químicas encontradas nas águas subterrâneas, justificando padrões incomuns na ausência de atividades antrópicas (FERRAZ; VALADÃO, 2005).

Dentro dos padrões avaliados, nesse trabalho, o pH da água é um fator primordial nos processos de coagulação, desinfecção e abrandamento das águas, assim no controle da corrosão e no tratamento dos esgotos. Valores foras da faixa recomendada ao consumo ( $\mathrm{pH}$ entre 6 e 9) interfere na palatabilidade, aumentando a formação de crustrações (VON SPERLING, 1996). Embora os valores que representem condições ácidas estejam relacionados a provável contaminação, o processo de desinfecção se processa melhor com águas que tenham pH ácido. Nossos achados apresentam um percentual de $50 \%$ de amostras com moderada acidez ( $\mathrm{pH}$ inferior a 6), que embora esteja associado a provável contaminação, essa discreta acidez favorece a adoção de futuros processos de desinfecção.

O oxigênio dissolvido é um indicador da concentração de oxigênio na água e de sua carga de poluição (VERNIER, 1994). O oxigênio dissolvido esteve alterado em todas as aldeias, tanto em águas de origem superficial quanto subterrâneas, com forte predominância no período intermediário e chuvoso $(\leq 6 \mathrm{mg} / \mathrm{l})$. Por outro lado, é considerada como turbidez a transparência da água, sendo função do teor de material particulado suspenso. Água com elevado teor de turbidez é indicativo de um alto conteúdo orgânico e inorgânico suspenso, que pode servir de abrigo para microrganismos e diminuir a eficiência do tratamento químico ou físico da água (VON SPERLING, 1996). As alterações encontradas nesse estudo foram iguais para os períodos seco e intermediário, embora em dois pontos encontraram-se valores acima de 1000 NTU (pontos: AP5/AP6) no período seco (VMP <40 NTU). Esses pontos foram os mesmos que apresentaram alterações em relação ao oxigênio dissolvido, fortalecendo a associação entre conteúdo orgânico e inorgânico suspenso com elevação da turbidez.

A capacidade que a água tem de transmitir corrente elétrica é definida como condutividade elétrica (CE), sendo dependente do seu teor de íons dissolvidos $\left(\mathrm{Na}^{+}, \mathrm{K}^{+}, \mathrm{Ca}^{2+}, \mathrm{Mg}^{2+}, \mathrm{NH}_{4}^{+}, \mathrm{Cl}\right.$, $\left.\mathrm{SO}_{4}{ }^{2-}, \mathrm{NO}_{3}, \mathrm{NO}_{2}, \mathrm{HCO}_{3}{ }^{-}\right) . \grave{\mathrm{A}}$ medida que a temperatura e a concentração de íons aumenta, a condutibilidade também aumenta proporcionalmente, tornando-a um bom indicador na avaliação das concentrações minerais e dos riscos que o excesso desses minerais podem promover na saúde (FERREIRA, 1997; GHEYI; QUEIROZ; DE MEDEIROS, 1997). Nesse estudo, 50\% das amostras apresentaram-se alteradas, em relação a condutividade $(<100 \mu \mathrm{S})$, em todos os períodos sazonais e em condições normais de temperatura (média $26,2{ }^{\circ} \mathrm{C}$ ). A maioria das fontes de águas subterrâneas tiveram essa análise alterada, fortalecendo a necessidade de estudos mais sensíveis quanto a presença de quais sais dissolvidos estão presentes nestas fontes e a relação destes com a constituição geológica desse solo nas condições químicas da água.

$\mathrm{O}$ nitrato $\left(\mathrm{NO}_{3}\right.$ ) é a principal configuração do nitrogênio encontrada nas águas. Em locais que apresentam elevadas concentrações de $\mathrm{NO}_{3}$, geralmente superiores a 5,0 mg/L, pressupõe-se que foram enriquecidos por atividades antropogênicas que envolvem compostos nitrogenados como fertilizantes solúveis, sistemas sépticos humanos ou esterco de animais domésticos. Nossas análises encontraram cinco alterações para essa avaliação (VMP $<10 \mu \mathrm{g} / \mathrm{L}$ ), embora três delas com valores muito próximos ao limite preconizado. O valor mais elevado (160,71 $\mathrm{mg} / \mathrm{L}$ ) foi observado no período seco, podendo ser associado à atividades antropogênicas, nesse 
caso, a condições sanitárias inadequadas com evacuações nas margens dos rios e córregos (ALABURDA; NISHIHARA, 1998; ASSIS et al., 2013). Em virtude do consumo de água in natura nos momentos de recreação neste córrego, faz-se necessária uma atenção especial em relação aos nitratos no período de estiagem.

A determinação da concentração dos coliformes totais e termotolerantes assumem importância como parâmetro indicador da possibilidade da existência de micro-organismos patogênicos, responsáveis pela transmissão de doenças de veiculação hídrica, tais como febre tifóide, febre paratifóide, disenteria bacilar e cólera (ROITMAN; TRAVASSOS; AZEVEDO, 1988). A maioria das bactérias do grupo coliforme pertence aos gêneros Escherichia, Citrobacter, Klebsiella e Enterobacter, embora vários outros gêneros e espécies pertençam ao grupo. Tanto os coliformes totais, quanto os termotolerantes, foram encontrados em valores acima do preconizado nesse estudo em mais de $70 \%$ das amostras (ausência de E. coli em 100 $\mathrm{ml}$ ). Suas alterações foram observadas em todos os momentos climáticos, em todas as aldeias, e independentemente da origem da água (superficial e subterrânea). Nos preocupa o fato de $100 \%$ das fontes subterrâneas estarem contaminadas com coliformes termotolerantes, mostrando possível infiltração nessas fontes. $\mathrm{O}$ escoamento superficial, durante o período de chuva, é o fator que mais contribui para as alterações microbiológicas da qualidade das águas (TALLON et al., 2005), entretanto, nossos achados foram superiores nos períodos seco e intermediário, afastando a ideia do escoamento como único fator casual para essa contaminação.

A comunidade indígena Maxakali vem sofrendo com repetitivos surtos de diarreia, com impacto direto nas crianças, e comprometendo os indicadores de morbidade e mortalidade (BRASIL, 2013). Em um estudo transversal, realizado no ano de 2009, foram identificados altos níveis de prevalências de parasitos intestinais em amostras de fezes (89\%), incluindo taxas de poliparasitismo acima de $70 \%$ e presença elevada de E. coli, principalmente entre os indivíduos menores de 12 anos de idade nesse grupo (ASSIS et al., 2013). A exemplo do encontrado em outros estudos (BEVILACQUA et al., 2002; TEIXEIRA et al., 2014), os hábitos inadequados de higiene, a defecação nas matas e margens próximas as fontes de água, assim como o descarte inadequado do lixo, constituem fatores que comprometem a potabilidade da água em todas as aldeias, justificando achados anteriores de parasitoses na mesma população e região
(ASSIS et al., 2013).

Dentre as possíveis limitações do presente estudo, destaca-se que todas as análises realizadas para os parâmetros investigados não foram avaliadas em duplicata.

\section{CONCLUSÕES}

As águas nas aldeias Indígenas Maxakali apresentaram condições físico-químicas e microbiológicas que a tornam imprópria ao consumo, com risco de adoecimento em virtude da sua condição sanitária. Dessa forma, a ausência de saneamento, assim como o desconhecimento ou a não aceitação de processos simples de desinfecção para a utilização da água, principalmente para o consumo, tem colocado a comunidade Maxakali em situação de vulnerabilidade para o adoecimento por doenças de veiculação hídrica. Existe, portanto, uma grande necessidade de novos estudos, que visem a continuar o monitoramento e avaliação da qualidade da água utilizada por esta comunidade nos dias atuais, assim como a necessidade de planejamento e implementação de um serviço de saneamento nas aldeias para garantir padrões mínimos de potabilidade da água. A adoção de processos de filtragem ou de tratamentos convencionais, que não afete a palatabilidade, são potenciais medidas eficazes a serem adotadas.

\section{REFERÊNCIAS}

ALABURDA, J.; NISHIHARA, L. Presença de compostos de nitrogênio em águas de poços. Revista de Saúde Pública, v. 32, n. 2, p. 160165, 1998. http://dx.doi.org/10.1590/S003489101998000200009

AMARAL, L. A. et al. Água de consumo humano como fator de risco à saúde em propriedades rurais. Revista de Saúde Pública, v. 37, n. 4, p. 510-514, 2003. http://dx.doi.org/10.1590/S003489102003000400017

APHA - American Public Health Association. Standard Methods for the Examination of Water e Wastewater, 22 ed. Washington, NW, 2012.

ASSIS, E. M. et al. Prevalência de parasitos intestinais na comunidade indígena Maxakali, Minas Gerais, Brasil, 2009. Cadernos de Saúde Pública, v. 29, n. 4, p. 681-690, 2013. 
http://dx.doi.org/10.1590/S0102-

311X2013000400006

BEVILACQUA, P. D. et al. Perfil parasitológico e qualidade da água para consumo humano: aplicação da metodologia da avaliação de risco.

Revista Brasileira de Epidemiologia, Suplemento Especial:454, 2002.

BRASIL. Ministério do Meio Ambiente. Resolução 357, de 17 de março de 2005. Dispõe sobre a classificação dos corpos de água e diretrizes ambientais para o seu enquadramento, bem como estabelece as condições e padrões de lançamento de efluentes, e dá outras providências. Conselho Nacional do Meio Ambiente-CONAMA. Diário Oficial da República Federativa do Brasil, Brasília, DF, 18 mar. 2005. Disponível em:

http://www.mma.gov.br/port/conama/legiabre.cf m?codlegi=459 >. Acesso em: 02 jun. 2016 .

Ministério do Meio Ambiente. Resolução $n^{\circ}$ 396, de 3 de abril de 2008 . Dispõe sobre a classificação e diretrizes ambientais para o enquadramento das águas subterrâneas e dá outras providências. Diário Oficial da República Federativa do Brasil, Brasília, DF, 07 abril. 2008. Disponível em: < http://www.mma.gov.br/port/conama/legiabre.cf m?codlegi=562 >. Acesso em: 14 jun. 2016.

- Fundação Nacional de Saúde. Manual prático de análise de água. 3. ed. Brasília: Funasa, 2009.

Ministério da Saúde. Portaria no 2914, de 12 de dezembro de 2011. Dispõe sobre os procedimentos de controle e de vigilância da qualidade da água para consumo humano e seu padrão de potabilidade. Diário Oficial da República Federativa do Brasil, Brasília, DF, 14 dez. 2011. Disponível em: <http://bvsms.saude.gov.br/bvs/saudelegis/gm/20 11/prt2914_12_12_2011.html >. Acesso em: 18 nov. 2016.

Ministério da Saúde. Sistema de Informação da Atenção à Saúde Indígena 2013. Brasília, DF. Disponível em: < http://portalms.saude.gov.br/saude-

indigena/gestao/siasi >. Acesso em: 20 jul. 2015.

BROOKS, G. F. et al. Microbiologia Médica de Jawetz, Melnick \& Adelberg. 26 ed. Porto Alegre: AMGH Editora, 2014

CARVALHO, M. A.; ALVES, T. C. G. A relação natureza e cultura entre os Maxakali: formulando conceitos. In: SEMINÁRIO VISÕES DO VALE, 2009, Anais... Belo Horizonte, Visões do Vale. 2009.

CETESB - Companhia Ambiental do Estado de São Paulo. Guia nacional de coleta e preservação de amostras: àgua, sedimento, comunidades aquáticas e efluentes líquidos. Org. Carlos Jesus Brandão...[et al.]. São Paulo: CETESB, 2011.

DIEGUES, A. C. S. Ilhas e mares: simbolismo e imaginário. São Paulo: Hucitec, 1998.

FERNANDES, Â. M. F. Diagnóstico da qualidade da água subterrânia em propriedade rural no município de Planalto, RS. 2012. Monografia (Curso de Geografia) - Departamento de Humanidades e Educação da Universidade Regional do Noroeste do Estado do Rio Grande do Sul-UNIJUI, Ijuí, 2012.

FERRAZ, C. M. L.; VALADÃO, R. C. Barreiras: formação ou grupo? (contribuições da análise geomorfológica do litoral sul da Bahia e das" chapadas" do Jequitinhonha). In: CONGRESSO ABEQUA, 10., 2005, Guarapari. Resumos Expandidos... Guarapari: ABEQUA, 2005.

FERREIRA, P. A. Aspectos físico-químicos do solo. In: GHEI, H. R.; QUEIROZ, J. E.; MEDEIROS, J. F. Manejo e controle da salinidade na agricultura irrigada. Campina Grande: UFPB/SBEA, 1997.

GHEYI, H. R.; QUEIROZ, J. E.; DE MEDEIROS, J. F. Manejo e controle da salinidade na agricultura irrigada. Campina Grande: UFPB/SBEA, 1997.

GIACOMETTI, L. Qualidade microbiológica, concentração de nitratos em águas de consumo alternativo (minerais e de poços) da cidade de Jaboticabal-SP. 2001. Dissertação (Mestrado em Microbiologia) Faculdade de Ciências Agrárias e Veterinárias da Universidade Estadual Paulista, São Paulo, 2001.

GONÇALVES, M. L. C.; ARAÚJO, A. ; FERREIRA, L. F. Human intestinal parasites in the past: new findings and a review. Memorias do Instituto Oswaldo Cruz, v. 98, p. 103-118, $2003 . \quad$ http://dx.doi.org/10.1590/S007402762003000900016

LAS CASAS, R. Saúde maxakali, recursos de cura e gênero: análise de uma situação social. 2007. Dissertação (Mestrado em Saúde Coletiva) - Instituto de Medicina Social da Universidade do Estado do Rio de Janeiro, Rio de Janeiro, 2007.

MACÊDO, J. A. B. Águas \& águas. São Paulo: Livraria Varela, 2001.

PELCZAR JR, M. J. et al. Microbiologia: conceitos e aplicações. 2 ed. São Paulo: Makron Books, 1996.

PIERZYNSKI, G. M.; VANCE, G. F.; SIMS, J. T. Soils and environmental quality. Boca Raton: CRC press, 2005.

QUEIROZ, M. F. et al. A qualidade da água de 
consumo humano e as doenças diarréicas agudas no Município do Cabo de Santo Agostinho, PE. Revista Brasileira de Epidemiologia, v. Suplemento Especial:456, 2002.

RAZZOLINI, M. T. P.; GÜNTHER, W. M. R. Impactos na saúde das deficiências de acesso a água. Saúde e Sociedade, v. 17, n. 1, p. 21-32, 2008. http://dx.doi.org/10.1590/S010412902008000100003

ROITMAN, I.; TRAVASSOS, L. R.; AZEVEDO, J. L. Tratado de microbiologia. São Paulo: Manole, 1988.

ROMERO, J. A. R. Análise espacial da pobreza municipal no Estado de Minas Gerais, 1991-2000. In: ENCONTRO NACIONAL DE ESTUDOS POPULACIONAIS, 14., 2006 Anais... Caxambu: ABEP, 2006.
TALLON, P. et al. Microbial indicators of faecal contamination in water: a current perspective. Water, Air, and Soil Pollution, v. 166, n. 1-4, $\mathrm{p}$ 139-166, 2005.

http://dx.doi.org/10.1007/s11270-005-7905-4

TEIXEIRA, J. C. et al. Estudo do impacto das deficiências de saneamento básico sobre a saúde pública no Brasil no periodo de 2001 a 2009. Engenharia Sanitaria e Ambiental, v. 19, n. 1, p. 87-96, 2014. http://dx.doi.org/10.1590/S1413-

41522014000100010

VERNIER, J. O meio ambiente. Campinas: Papirus, 1994.

VON SPERLING, M. Introdução à qualidade das águas e ao tratamento de esgotos. Belo Horizonte: Editora UFMG, 1996. 